\begin{tabular}{|c|c|c|}
\hline \multirow{3}{*}{$\begin{array}{r}\text { Case Reports in } \\
\text { Gastroenterology }\end{array}$} & \multirow{2}{*}{\multicolumn{2}{|c|}{ Case Rep Gastroenterol 2014;8:107-114 }} \\
\hline & & \\
\hline & $\begin{array}{l}\text { DOI: 10.1159/000361012 } \\
\text { Published online: Vlarch 27, } 2014\end{array}$ & $\begin{array}{l}\text { (c) } 2014 \text { S. Karger AG, Basel } \\
\text { 1662-0631/14/0081-0107\$39.50/0 } \\
\text { www.karger.com/crg }\end{array}$ \\
\hline & \multicolumn{2}{|c|}{$\begin{array}{l}\text { This is an Open Access article licensed under the terms of the Creative Common } \\
\text { Attribution-NonCommercial } 3.0 \text { Unported license (CC BY-NC) (www.karger.com/OA } \\
\text { license), applicable to the online version of the article only. Distribution permitted for non } \\
\text { commercial purposes only. }\end{array}$} \\
\hline
\end{tabular}
commercial purposes only.

\title{
Gastric Cancer Arising from an Upside-Down Stomach through a Paraesophageal Hiatal Hernia
}

\author{
Kenji Mimatsu ${ }^{a}$ Hisao Kano $^{a}$ Takatsugu Oida $^{a}$ Atsushi Kawasaki ${ }^{a}$ \\ Nobutada Fukino $^{\mathrm{a}}$ Kazutoshi Kida $^{\mathrm{a}}$ Youichi Kuboi $^{\mathrm{a}}$ Sadao Amano ${ }^{\mathrm{b}}$ \\ ${ }^{a}$ Department of Surgery, Social Insurance Yokohama Central Hospital, Yokohama, and \\ ${ }^{b}$ Department of Breast and Endocrine Surgery, Nihon University School of Medicine, \\ Tokyo, Japan
}

\section{Key Words}

Paraesophageal hiatal hernia · Upside-down stomach · Gastric cancer

\begin{abstract}
We report the rare case of an elderly patient with an advanced gastric cancer arising from an upside-down stomach through a paraesophageal hiatal hernia (PEH). An 82-year-old man presented with appetite loss and anemia. Upper gastrointestinal endoscopy revealed a type 1 tumor located in the middle body of the stomach. An upper gastrointestinal series and computed tomography showed organoaxial rotation of the stomach, which was located in the mediastinum, through a $\mathrm{PEH}$, indicating an upside-down stomach. The preoperative diagnosis was gastric cancer arising from an upside-down stomach through a $\mathrm{PEH}$. The patient underwent total gastrectomy with lymph node dissection and closure of the hernial orifice. Although a large PEH is a chronic disorder, gastric malignancies should be considered in patients with PEH manifested as an upside-down stomach due to its anatomical characteristics, and careful preoperative diagnosis is mandatory.

(c) 2014 S. Karger AG, Basel
\end{abstract}

\section{Introduction}

Paraesophageal hiatal hernia (PEH) is a condition in which intra-abdominal organs herniate into the thoracic space through the esophageal hiatus. It is the most common type of diaphragmatic hernia. Although the precise sequence of events leading to PEH development is not completely understood, it is likely that the process involves progressive weakening and stretching of the phrenoesophageal membrane along with weakening and 
Mimatsu et al.: Gastric Cancer Arising from an Upside-Down Stomach through a Paraesophageal Hiatal Hernia

enlargement of the diaphragmatic hiatus. PEH most commonly affects infants and the elderly. In infancy, congenital defects trigger this disease, whereas in adults, weakening of the supportive tissue of the lower esophagus or high abdominal pressure associated with a humpback and obesity may cause this event. Since their first description in 1926 by Akerlund [1], translocations of the stomach along its long axis through the esophageal diaphragmatic hiatus have been classified into four types: sliding (type I), paraesophageal (type II), mixed-form (type III) and upside-down stomach (type IV) hiatal diaphragmatic hernia. Upside-down stomach is one of the major forms of PEH classified by Bettex and Kuffer [2], and it describes a condition wherein a large part of the stomach is migrated into the thoracic space accompanied by gastric organoaxial rotation. A PEH incarcerated with an intrathoracic gastric volvulus is common; however, an upside-down stomach is a rare type of PEH. Gastric cancer is often complicated by PEH; however, advanced gastric cancer arising from an upside-down stomach associated with PEH is extremely rare $[3,4]$. This report describes the case of an elderly patient with an advanced gastric cancer arising from an upside-down stomach through a PEH; in addition, we present a short review of the relevant literature.

\section{Case Report}

An 82-year-old man was admitted to our hospital because of appetite loss and anemia. His medical history included chronic obstructive pulmonary disease and dementia. On physical examination, he was $150 \mathrm{~cm}$ tall and weighed $45 \mathrm{~kg}$. His abdomen was soft and flat and showed no palpable masses. Laboratory tests revealed hypohemoglobinemia $(\mathrm{Hb}$ $7.5 \mathrm{~g} / \mathrm{dl}$ ) and hypoproteinemia (albumin $2.5 \mathrm{~g} / \mathrm{dl}$ ); all other results were normal. Upper gastrointestinal endoscopy showed a type 1 hemorrhagic tumor located in the middle body of the stomach, although observation of the entire stomach was impossible because of extreme transformation. An upper gastrointestinal series showed organoaxial rotation of the body of the stomach with the entire stomach located in the mediastinum, which is indicative of upside-down stomach. The tumor was present in the upside-down stomach through a PEH (fig. 1a). Pathological analysis of biopsy specimens revealed moderately differentiated tubular adenocarcinoma. Coronal computed tomography images showed an organoaxial gastric volvulus and sliding up through a PEH (fig. 1b). A gastric tumor was detected in the upside-down stomach through the PEH and lymph node metastases were observed surrounding the stomach; however, liver metastases and peritoneal dissemination were not observed. Preoperative staging according to the TNM classification of gastric cancer was T3N2M0, stage IIIA. On the basis of the preoperative diagnosis of gastric cancer arising from an upside-down stomach through a PEH, the patient underwent surgical treatment.

Surgery was performed via a median laparotomy incision. The entire stomach was found to be herniated through the enormously dilated hiatus into the left thorax together with the greater omentum (fig. 2a). The hernial orifice was approximately $5 \mathrm{~cm}$ in diameter (fig. 2b). After the incarcerated stomach had been untwisted and reduced back into the abdomen, the tumor was found to be located in the middle body of the stomach; however, the short esophagus was not found in the state of esophagus. After reduction of the abdominal contents from the thoracic cavity, a total gastrectomy with a Roux-en-Y reconstruction and dissection of the lymph nodes surrounding the stomach was performed. The crura of the diaphragm were approximated with interrupted nonabsorbable sutures for closure of the hernial orifice. The jejunum just under the anastomosis was sutured to the crus to permanently fix the esophagojejunal anastomosis in an abdominal position (fig. 2c). In con- 
Mimatsu et al.: Gastric Cancer Arising from an Upside-Down Stomach through a Paraesophageal Hiatal Hernia

sideration of the patient's age and preoperative performance status, a jejunostomy was constructed as a route of enteral nutrition after surgery.

The resected specimen revealed a type 1 hemorrhagic tumor measuring approximately $7.7 \times 7.4 \mathrm{~cm}$ (fig. 3). Histopathological examination revealed a moderate tubular adenocarcinoma with vascular invasion and metastasis in three lymph nodes surrounding the stomach, and the final clinical stage was IIIA (T3N2M0) according to the TNM classification.

The postoperative course was uneventful. Roentgenography showed good passage without leakage of the anastomosis, and oral intake was initiated on postoperative day 7 , although no increase in food intake was achieved. Therefore, the energy deficit was supported by enteral nutrition through the jejunostomy. The patient was discharged 35 days after surgery, and there was no recurrence of cancer or hernia during 1-year follow-up.

\section{Discussion}

Although gastric cancer complicated by PEH is common, gastric cancer presenting in an upside-down stomach through the PEH is an extremely rare condition, and only 13 such cases have been previously reported [3-15]. Among these cases, including the present one (table 1), the mean patient age was 78.9 years and a higher incidence was found among women (male:female ratio $=3: 11$ ). The chief complaints were abdominal symptoms such as nausea and vomiting, and epigastralgia and thoracic symptoms such as heartburn, dyspnea and palpitations, which were not regarded as specific clinical symptoms in this pathological condition. The early detection of gastric cancer may be delayed because the symptoms of gastric cancer, including epigastric pain, nausea and weight loss, may be concealed by a large PEH [14]. Gastric cancer arising through an upside-down stomach through a PEH tends to be advanced (advanced type:early type $=76.9: 23.1 \%$ ), and $46.1 \%$ of patients show stage III and IV tumors. The tumor tends to be relatively large (mean diameter $69.8 \mathrm{~mm}$ ) at the time of initial diagnosis, as evaluation is often delayed because the symptoms are thought to arise from the coexisting large PEH. On histopathology, $42.8 \%$ of such patients have moderately differentiated adenocarcinoma, $35.7 \%$ have poorly differentiated adenocarcinoma and $7.1 \%$ have well-differentiated adenocarcinoma, signet ring cell carcinoma or large-cell neuroendocrine carcinoma. The surgical treatment consists of relocation of the herniated stomach, standard treatments for gastric cancer according to the stage of cancer progression and repair of the hernial orifice. Among the 14 reported patients, including the present one, 7 underwent total gastrectomy, 5 underwent distal gastrectomy, 1 underwent proximal gastrectomy and 1 was administered chemotherapy. The mean diameter of the hiatus was $64.1 \mathrm{~mm}$. Closure of the hernial orifice was performed in 12 cases among the 13 cases treated surgically. Anastomotic leakage occurred in 1 case each of total and proximal gastrectomy. Anastomotic dehiscence may have resulted from the change in negative and positive pressures caused by breathing after closure of the hernial orifice, which may affect the anastomotic site [12]. However, whether closure of the hernial orifice affects anastomotic dehiscence is unclear because anastomotic leakage occurred in 1 patient who underwent hernial orifice closure and in 1 patient in whom it was not closed [4].

The relationship between PEH and gastric cancer remains controversial. Chronic reflux, also known as gastroesophageal reflux disease, is emerging as one of the strongest risk factors for adenocarcinoma of the esophagus and gastric cardia [16]. MacDonald and MacDonald [17] reported that patients with such cancers show a high prevalence of coexisting PEH. Chow et al. [18] reported a significant two-fold or greater risk of adenocarcinoma of the esophageal and gastric cardia associated with a history of functional reflux of 
Mimatsu et al.: Gastric Cancer Arising from an Upside-Down Stomach through a Paraesophageal Hiatal Hernia

gastric juice into the esophagus, hiatal hernia, esophagitis, esophageal ulcer and dysphagia. Lagergren et al. [19] also evaluated the association between weekly reflux frequency and risk of adenocarcinoma of the esophagus in a Swedish study. Reflux symptoms arising more than three times per week were associated with an odds ratio of 16.7 (95\% confidence interval 8.7-28.3) compared with the absence of reflux symptoms. Gastroesophageal reflux was only weakly associated with risk of adenocarcinoma of the gastric cardia (odds ratio 2.3, 95\% confidence interval 1.2-4.3; >3 times/week vs. none). Moreover, Wu et al. [20] reported a relationship between hiatal hernia with symptoms of gastric juice reflux and carcinomas of the esophageal and gastric cardia. The physicochemical stimulation of gastric juice reflux due to reflux esophagitis is an important factor in the development of carcinoma; however, there is no direct evidence for such a relationship between gastric carcinogenesis and PEH [21]. Therefore, several studies suggested that regular follow-up examinations by upper gastrointestinal endoscopy are important in patients with PEH to assess the possible occurrence of gastroesophageal malignancies $[3,4,8,12]$.

In conclusion, although PEH is a common chronic disorder, an upside-down stomach is a rare type of PEH. Moreover, gastric cancer arising from an upside-down stomach through a $\mathrm{PEH}$ is extremely rare. Early detection of gastric cancer may be delayed because the symptoms of gastric cancer are concealed by large PEH, and also an accurate diagnosis of gastric cancer and observation of the entire stomach using endoscopy may be impossible because of extreme gastric transformation. We should consider gastric malignancies in patients with a PEH and perform careful regular follow-up examinations by upper gastrointestinal endoscopy.

\section{Disclosure Statement}

There are no financial or other relations that could lead to a conflict of interest.

\section{References}

1 Akerlund A: Hernia diafragmatica hiatus oesophagei vom anatomischen und röntgenologischen Gesichts-punkt. Acta Radiol 1926;6:3-22.

2 Bettex M, Kuffer F: Long-term results of fundoplication in hiatus hernia and cardio-esophageal chalasia in infants and children. Report of 112 consecutive cases. J Pediatr Surg 1969;4:526-530.

-3 Iso Y, Tagaya N, Nemoto T, Kita J, Sawada T, Kubota K: Incarceration of a large cell neuroendocrine carcinoma arising from the proximal stomach with an organoaxial gastric volvulus through an esophageal hiatal hernia: report of a case. Surg Today 2009;39:148-152.

4 Kominami H, Kawasaki K, Tanaka K, Kaneji S, Fujino Y, Tominaga M: A case of advanced gastric cancer with hiatal hernia associated with the upside down stomach (in Japanese with English abstract). Nihon Rinshyogeka Igakkaizasshi (J Jpn Surg Assoc) 2012;73:3129-3134.

5 Izumi Y, Tsuchiya K, Maeda H, Mukubou M, Asahara M, Sakaguchi T: A case of gastric cancer complicated with esophageal hiatal hernia with upside-down stomach (in Japanese). Gekashinryo 1993;9:1181-1185.

-6 Narayan D, Soybes D, Salem RR: Pyloric carcinoma presenting as intrathoracic volvulus. J Clin Gastroenterol 1994;18:260-261.

7 Sato K, Midorikawa Y, Kamiga M, Kumbota Y: A case of gastric cancer associated with esophageal hiatus hernia presenting with upside down stomach (in Japanese). Nihon Shokakibyo Gakkaizasshi 1996;93: 26-29.

8 Matsuda M, Aikawa T, Sekikawa T, Karikomi K, Iizuka H, Fujii H, et al: Advanced gastric carcinoma within 'upside-down-stomach' due to mixed esophageal hiatal hernia - report of a case (in Japanese with English abstract). Nihon Syokakigeka Gakkaizasshi (Jpn J Gastroenterol Surg) 1997;30:994-998.

9 Seshimo T, Ito M, Monden K, Mizukami T: A case of advanced gastric cancer within sliding hiatal hernia associated with organoaxial gastric volvulus (in Japanese with English abstract). Nihon Syokakigeka Gakkaizasshi (Jpn J Gastroenterol Surg) 1999;32:2243-2247. 


\begin{tabular}{l|l}
\hline \multicolumn{2}{l}{ Case Rep Gastroenterol 2014;8:107-114 } \\
\hline DOI: $10.1159 / 000361012$ & $\begin{array}{l}\text { C 2014 S. Karger AG, Basel } \\
\text { www.karger.com/crg }\end{array}$ \\
\hline
\end{tabular}

Mimatsu et al.: Gastric Cancer Arising from an Upside-Down Stomach through a Paraesophageal Hiatal Hernia

10 Kawai S, Matsuura Y, Kouno H, Kitagawa Y, Yamanaka H, Hiramatsu K: A case of quadruple gastric cancer within upside down stomach due to esophageal hiatal hernia (in Japanese with English abstract). Nihon Rinshyogeka Igakkaizasshi (J Jpn Surg Assoc) 2001;62:376-380.

11 Horiba K, Yamashita K, Tanaka N, Kyono S, Yokoi K, Higuchi K, et al: A case of gastric cancer associated with esophageal hiatus hernia presenting horizontal torsion of the stomach (in Japanese with English abstract). Prog Digest Endosc 2001;59:48-51.

12 Tsutani Y, Kurita A, Aogi K, Kubo Y, Tanada M, Takashima S: A case of gastric cancer in an 'upside down stomach' due to esophageal hiatal hernia (in Japanese with English abstract). Nihon Rinshyogeka Igakkaizasshi (J Jpn Surg Assoc) 2003;66:1328-1332.

13 Shibuya M, Teraoka H, Nakao S, Mashita K, Hara J, Nitta A: A case of gastric cancer associated with large esophageal hiatus hernia presenting with upside down stomach and incarcerated colon (in Japanese). Rynshogeka 2010;65:1049-1053.

14 Takahashi M, Kodera K, Fujiwara H, Chiba T, Sasaki A, Wakabayashi G: A case of gastric cancer resection in a patient with an esophageal hiatal hernia and an upside down stomach (in Japanese with English abstract). Nihon Rinshyogeka Igakkaizasshi (J Jpn Surg Assoc) 2010;71:1501-1506.

15 Toyokawa T, Teraoka H, Kitayama K, Nomura S, Kanehara I, Nishio H: Laparoscopic surgery for gastric cancer and esophageal hiatal hernia complicated by an 'upside down stomach' - a case report. Nihon Rinshyogeka Igakkaizasshi (J Jpn Surg Assoc) 2013;74:931-935.

16 Mayne ST, Navarro SA: Diet, obesity and reflux in the etiology of adenocarcinomas of the esophagus and gastric cardia in humans. J Nutr 2002;132(11 suppl):3467S-3470S.

17 MacDonald WC, MacDonald JB: Adenocarcinoma of the esophagus and/or gastric cardia. Cancer 1987;60: 1094-1098.

18 Chow WH, Finkle WD, McLaughlin JK, Frankl H, Ziel HK, Fraumeni JF Jr: The relation of gastroesophageal reflux disease and its treatment to adenocarcinomas of the esophagus and gastric cardia. JAMA 1995;274: 474-477.

19 Lagergren J, Bergstrom R, Lindgren A, Nyren O: Symptomatic gastroesophageal reflux as a risk factor for esophageal adenocarcinoma. N Engl J Med 1999;340:825-831.

20 Wu AH, Tseng CC, Bernstein L: Hiatal hernia, reflux symptoms, body size, and risk of esophageal and gastric adenocarcinoma. Cancer 2003;98:940-948.

21 Zheng T, Mayne ST, Holford TR, Boyle P, Liu W, Chen Y, Mador M, Flannery J: The time trend and ageperiod-cohort effects on incidence of adenocarcinoma of the stomach in Connecticut from 1955-1989. Cancer 1993;72:330-340. 


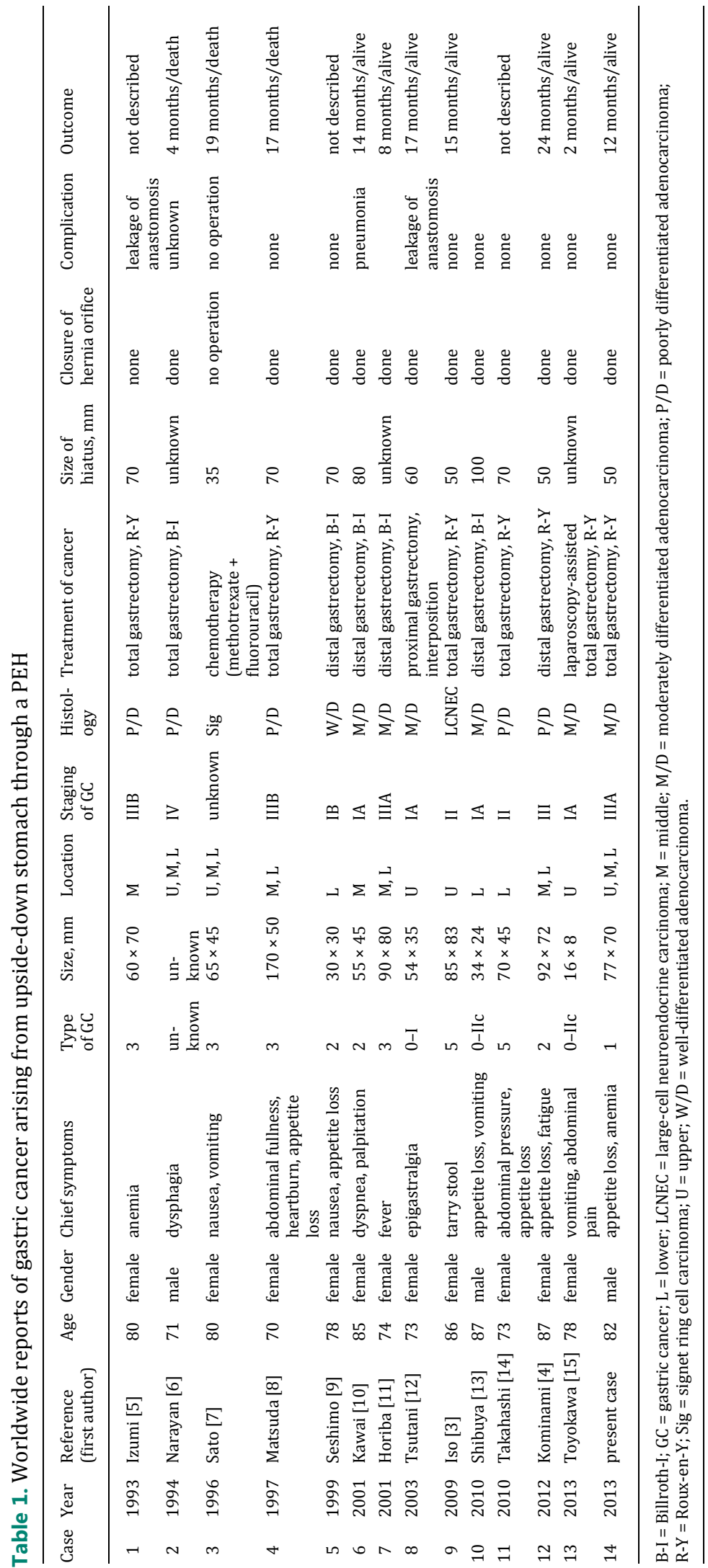




\section{Case Reports in
Gastroenterology}

\begin{tabular}{l|l}
\hline Case Rep Gastroenterol 2014;8:107-114 \\
\hline DOI: $10.1159 / 000361012$ & $\begin{array}{l}\text { @ 2014 S. Karger AG, Basel } \\
\text { www.karger.com/crg }\end{array}$ \\
\hline
\end{tabular}

Mimatsu et al.: Gastric Cancer Arising from an Upside-Down Stomach through a Paraesophageal Hiatal Hernia
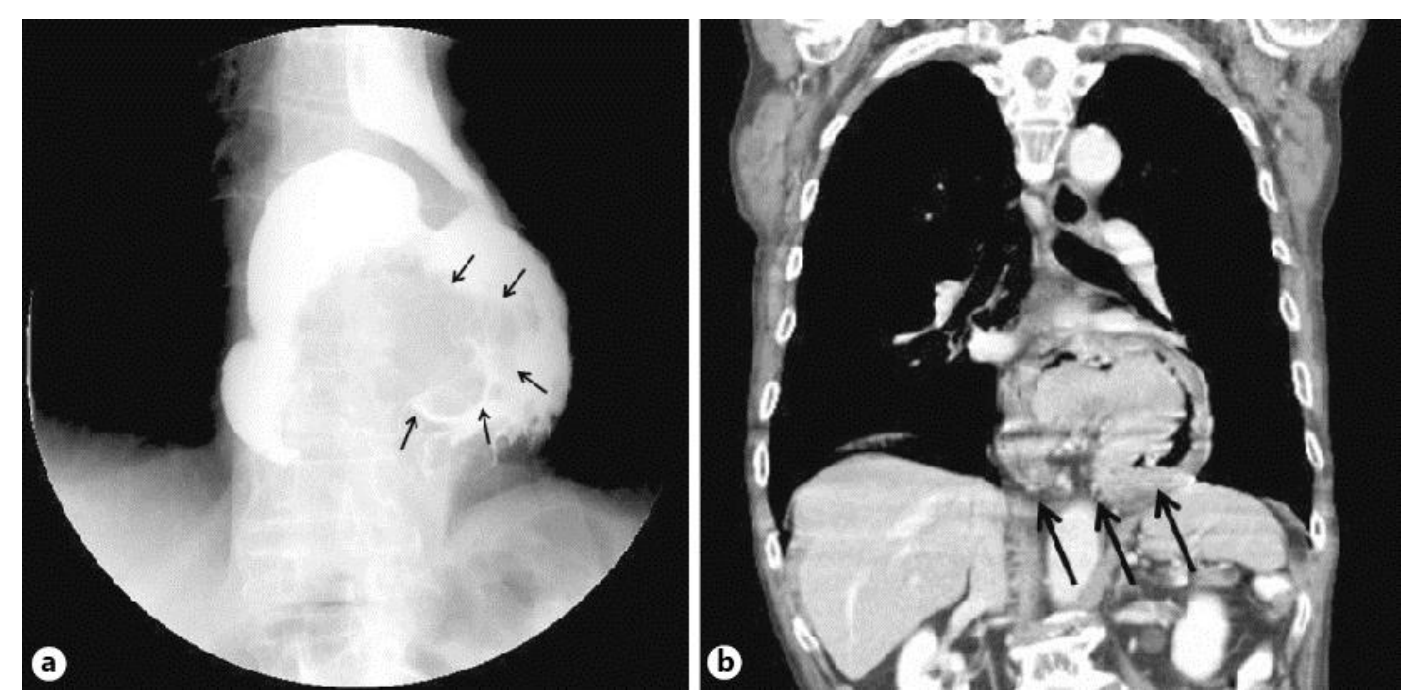

Fig. 1. a Upper esophagogastric series. The body of the stomach was located above the fundus, situated on the cephalic side, showing organoaxial rotation, and the entire stomach was located in the mediastinum, which indicated upside-down stomach. The gastric tumor (arrows) was found in the upper body of the stomach. b Coronal computed tomography images revealed that the entire stomach (arrows) was herniated into the mediastinum through the esophageal diaphragmatic hiatus.
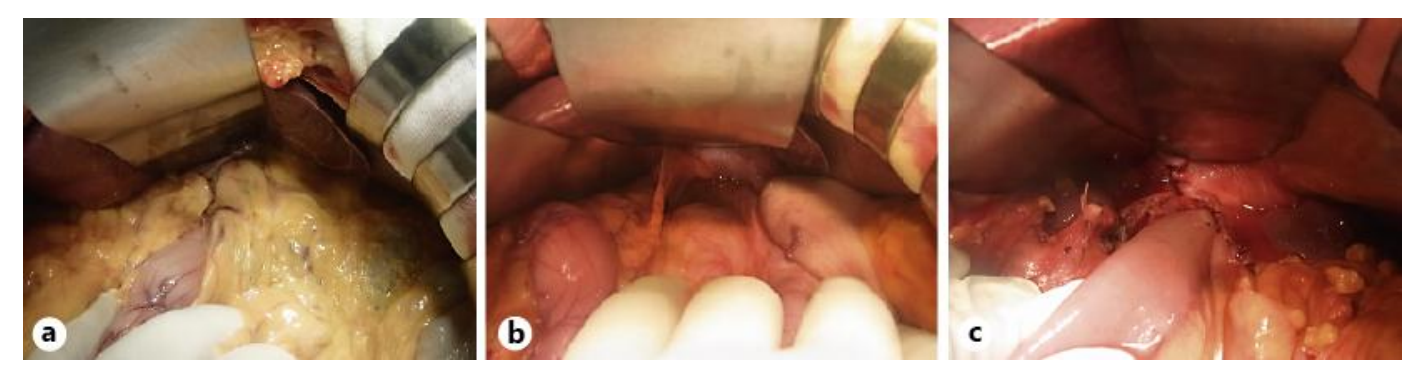

Fig. 2. Operative findings. a The entire stomach was found to be herniated through the enormously dilated hiatus into the left thorax together with the greater omentum. $\mathbf{b}$ The hernial orifice was found to be approximately $5 \mathrm{~cm}$ in diameter after the incarcerated stomach had been reduced back into the abdomen. c The crura of the diaphragm were closed and the jejunum just under the anastomosis was sutured to the crus to permanently fix the esophagojejunal anastomosis in an abdominal position. 
Mimatsu et al.: Gastric Cancer Arising from an Upside-Down Stomach through a Paraesophageal Hiatal Hernia

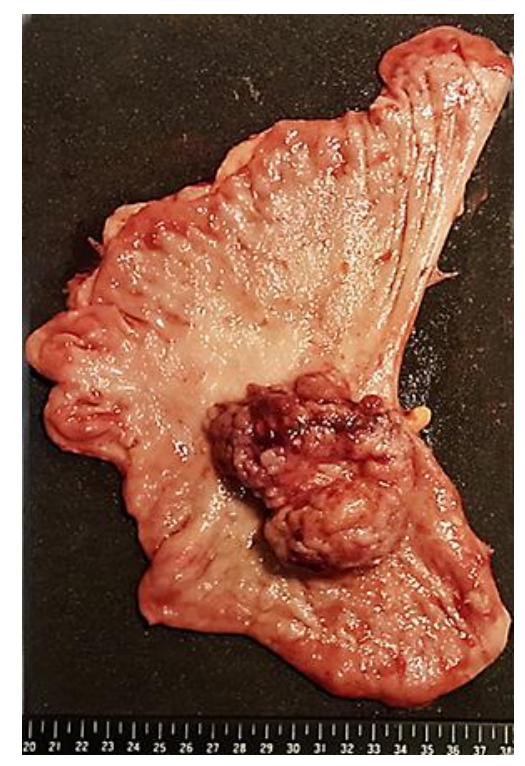

Fig. 3. Macroscopic finding showed a type 1 large tumor at the small curvature in the middle and upper body of the stomach. 